Additional Perspectives articles for Influenza: The Cutting Edge book collection are available at http://perspectivesinmedicine.cshlp.org/cgi/collection/influenza_the_cutting_edge.

\title{
The Structure, Function, and Pathobiology of the Influenza A and B Virus Ion Channels
}

\author{
Robert A. Lamb \\ Department of Molecular Biosciences, Howard Hughes Medical Institute, Northwestern University, Evanston, \\ Illinois 60208-3500, USA \\ Correspondence: ralamb@northwestern.edu
}

\begin{abstract}
Influenza A virus AM2 protein is an integral membrane protein that is an ion channel (also known as a viroporin). The channel has 24 extracellular residues, 19 residues that span the membrane once and acts as both the channel pore and also the membrane anchoring domain, and a 54-residue cytoplasmic tail. The M2 protein has four identical chains linked via two disulfide bonds that form a four-helix bundle that is $10^{7}-10^{8}$ more permeable to protons than $\mathrm{Na}^{+}$ions. The $\mathrm{M} 2$ channel is activated by low $\mathrm{pH}$, His residue 37 is the $\mathrm{pH}$ sensor, and Trp residue 41 is the channel gate. The channel is blocked by the antiviral drug amantadine hydrochloride. The influenza B virus BM2 protein does not have homology with the AM2 channel, but BM2 does have the His proton sensor, Trp gate, and is activated by low $\mathrm{pH}$. It is thought that the AM2 and BM2 proteins have common functions in the influenza $\mathrm{A}$ and $\mathrm{B}$ virus life cycles. Both BM2 and AM2 also facilitate virus budding. The amphipathic helix in the AM2 cytoplasmic tail has an important role in the assembly of the virus, and functional AM2 protein makes the virus independent of the "endosomal sorting complex required for transport" (ESCRT) complex scission.
\end{abstract}

$T_{s e t i n g}^{\text {he }}$ he influenza A virus genome consists of eight segments of negative-sense viral RNA. Each RNA segment is complexed with the heterotrimeric viral polymerase that consists of three subunits $\mathrm{PB} 1, \mathrm{~PB} 2$, and $\mathrm{PA}$. Together with the nucleoprotein (NP) and virion RNA, the complex forms the viral ribonucleoprotein (vRNP) particles. To date, the $\sim 13-\mathrm{kB}$ genome is known to encode 18 different proteins (Inglis et al. 1977; Palese 1977; Lamb et al. 1978, 1980; Lamb and Choppin 1979; Wise et al. 2012; Muramoto et al. 2013). The gene encoding the matrix protein (M1) produces four mRNAs: mRNA 1 is an unspliced transcript, which en- codes the M1 protein, the most abundant protein in the virion. mRNA 2 is spliced and encodes the M2 protein (Lamb and Choppin 1981), which is an ion channel. mRNA 4 encodes the M42 protein, which is M2 with a lengthen amino-terminal region and mRNA 3. M2 mRNA 3 is alternatively spliced to M2 RNA 2, does not encode a known protein, and is not required for virus growth in tissue culture (Jackson and Lamb 2008). In 2012, Jagger and colleagues identified a new protein PA-X encoded in an overlapping reading frame on RNA segment 3: PA-X is translated by frameshifting and $\mathrm{PA}-\mathrm{X}$ represses cellular gene expression in

Editors: Gabriele Neumann and Yoshihiro Kawaoka

Additional Perspectives on Influenza: The Cutting Edge available at www.perspectivesinmedicine.org

Copyright (C) 2020 Cold Spring Harbor Laboratory Press; all rights reserved; doi: 10.1101/cshperspect.a038505

Cite this article as Cold Spring Harb Perspect Med 2020;10:a038505 
R.A. Lamb

tissue culture, and in a mouse model of infection PA-X expression leads to increased inflammatory and apoptotic responses (Jagger et al. 2012).

\section{ARCHITECTURE OF THE M2 ION CHANNEL}

The 97-residue M2 protein is expressed at the apical surface of polarized cells (Hughey et al. 1992). The M2 protein consists of 24 extracellular residues, a 19-residue transmembrane domain that spans the membrane once, and a 54residue cytoplasmic tail. Residues $45-60$ form an amphipathic helix that is involved in virus budding and filament formation (Rossman et al. 2010a,b). The presence of an amino-terminal extracellular domain in the absence of a cleavable signal sequence indicates that M2 is a model type III integral membrane protein (von Heijne and Gavel 1988) that is dependent on the signal recognition particle for cotranslational insertion into the endoplasmic reticulum membrane (Hull et al. 1988). The M2 protein is abundantly expressed at the cell surface but is greatly underrepresented in virions with 20-60 molecules present in each virion (Zebedee et al. 1985; Zebedee and Lamb 1988). The M2 protein forms a homotetramer, sometimes called a dimer of dimers, and the M2 protein chains are linked by disulfide bonds (residues 17 and 19).

Oocytes are an ideal model system for electrophysiological experiments and many of the measurements of proton flux were made in oocytes of Xenopus laevis expressing the M2 protein. The channel is activated by low $\mathrm{pH}$ and is $10^{7}-10^{8}$ more permeable to protons than $\mathrm{Na}^{+}$ and $\mathrm{K}^{+}$(Chizhmakov et al. 1996; Pinto et al. 1996; Shimbo et al. 1996). The cation permeability of the M2 ion channel allows the ion channel to function as an antiporter facilitating the efflux of $\mathrm{Na}^{+}$and $\mathrm{K}^{+}$along with proton influx (Leiding et al. 2010). The selective nature of the ion channel is dependent on the four transmembrane domains whose polar and single charged residues face the lipid layer. Each of the four transmembrane domains form an $\alpha$ helix (Fig. 1). Each of the $\alpha$ helices consists of 3.6 residues per turn for residues $26-43$. The amino terminus of the ion channel is constricted by the hydrophobic side chain of residue 27 . Then the pore of the channel widens until residue 41 where it becomes constricted. Residue 37 is the proton sensor and conducts proteins by protonation/deprotonation of the imidazole (Pinto et al. 1997), and the side chain of Trp residue 41 acts as the gate of the channel (Duong-Ly et al. 2005; Cady et al. 2010).

\section{Properties of the Ion Channel}

Many studies on M2 function and activity have benefited from inhibition of the channel by the drug amantadine (Davies et al. 1964). As shown by solution nuclear magnetic resonance (NMR), solid phase NMR, and X-ray crystallography, amantadine blocks the M2 ion channel pore (Wang et al. 2001; Schnell and Chou 2008; Stouffer et al. 2008; Thomaston et al. 2015). Initial studies by Schnell and Chou (2008) placed amantadine at a low-affinity binding site on the outside of the four-helix bundle but this lowaffinity site is probably irrelevant biologically (Pielak et al. 2009). The tilt angle of the fourhelix bundle varies depending on the tilt angle of the helices. For a micelle of 1,2-dimyristoylsn-glycero-3-phosphocholine (DMPC), a tilt angle of $37^{\circ}$ was found, whereas in 1,2-dioleoyl-sn-glycero-3-phosphocholine (DOPC), an angle of $33^{\circ}$ was found (Nishimura et al. 2002; Duong-Ly et al. 2005; Yi et al. 2009; Hu et al. 2011; Gu et al. 2013). The M2 protein is posttranslationally modified by addition of palmitate to the M2 cytoplasmic tail at residue 50 and phosphorylation, predominantly at M2 residue 63 .

\section{Biological Function of the M2 Ion Channel}

Several mutations in the cytoplasmic tail of M2 tail have been identified that have been shown to inhibit virus assembly and budding (McCown and Pekosz 2005; Grantham et al. 2010; Liu et al. 2018). The cytoplasmic tail is modified in its cytoplasmic domain by the addition of ubiquitination at residue $\mathrm{K} 78$ and this posttranslational modification is crucial for production of infectious virus (Su et al. 2018). The cytoplasmic tail contains an $\alpha$-helical region (residues 45-61) that is essential for budding from the 
A

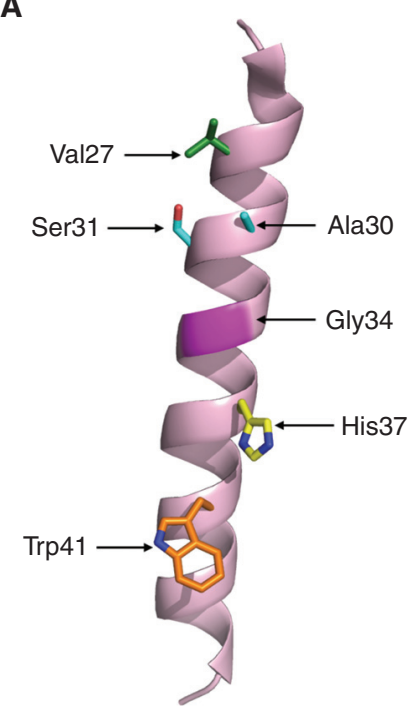

B

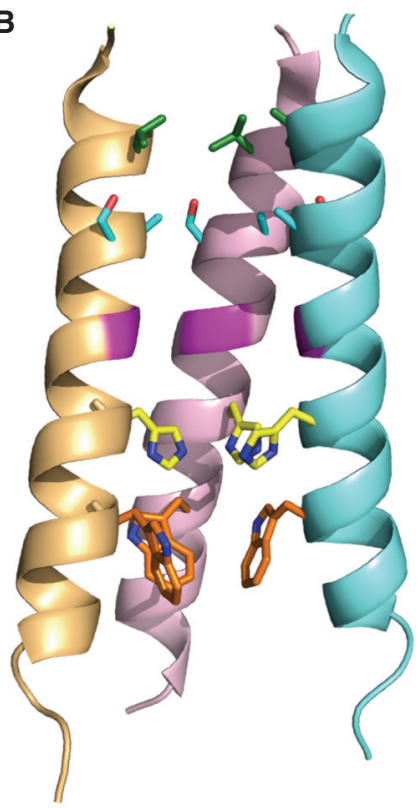

Figure 1. The three-dimensional structure of the influenza A virus M2 ion channel. (A) A monomer of the influenza A virus M2 transmembrane domain showing the amino acid residues that face the ion channel pore. $(B)$ The nuclear magnetic resonance (NMR) structure (PDB ID: 2RLF) (Schnell and Chou 2008) was used to create the diagram. The structure of the M2 channel determined by X-ray crystallography had the four $\alpha$ helices at a larger degree of tilt to each other (Stouffer et al. 2008).

plasma membrane. This region of M2 also contains a cholesterol recognition/interaction amino acid consensus (CRAC) domain and a LC3interacting region (residues 91-94) required to subvert autophagy and maintain virion stability (Beale et al. 2014). The AM2 cytoplasmic tail is highly conserved in sequence among strains and tyrosine resides in the cytoplasmic tail are required for the production of infectious particles (Grantham et al. 2010).

\section{EARLY EFFECTS OF AMANTADINE ON INFLUENZA VIRUS REPLICATION}

The M2 protein has an essential role in the life cycle of the virus. Mutants resistant to the effects of amantadine contained changes in the M2 transmembrane domain (Hay et al. 1985), and the effect of the drug was found to be at an early stage between the steps of penetration and uncoating. Later, it was found that amantadine treatment caused the M1 protein to fail to dissociate from the RNPs during uncoating and prevented the transport of the RNP complex to the nucleus (Hay et al. 1985; Zhirnov 1990; Martin and Heleniust 1991).

\section{LATE EFFECTS OF AMANTADINE ON INFLUENZA VIRUS REPLICATION}

In addition to the "early" effects of amantadine, the drug has a second "late" effect on the replication of some subtypes of avian influenza virus. These subtypes have a hemagglutinin that is cleaved intracellularly and have a high $\mathrm{pH}$ optimum of fusion (e.g., pH 5.7-6.0). In cells infected with highly pathogenic avian influenza viruses (e.g., Fowl Plague Virus, H7N9), amantadine causes a premature conformation change with hemagglutinin (HA) being converted to the low$\mathrm{pH}$ postfusion form (Sugrue et al. 1990; Ciampor et al. 1992a,b; Grambas and Hay 1992; Grambas et al. 1992). By using immunological and biochemical criteria, amantadine caused the form of HA to be indistinguishable from the low $\mathrm{pH}$-induced form of HA. Taken together, the 
R.A. Lamb

data led to the hypothesis that the function of the M2 protein is to act as a proton-selective ion channel that modulates the $\mathrm{pH}$ of intracellular compartments, principally the trans-Golgi network (TGN). When the channel is blocked by amantadine, the TGN is not acidified and uncoating of virus does not occur.

\section{INFLUENZA VIRUS M2 PROTEIN MEDIATES ESCRT-INDEPENDENT MEMBRANE SCISSION}

The budding of enveloped viruses is a complex multistep process, the completion of which requires alterations in membrane curvature at the neck of the budding virion. Many viruses use host "endosomal sorting complex required for transport” (ESCRT) proteins. However, influenza virus is thought to be ESCRT-independent and the AM2 protein has been shown to mediate virus budding. The highly conserved AM2 amphipathic helix that residues within its cytoplasmic tail has been shown to cause budding into giant unilamellar vesicles (Rossman et al. 2010b).

\section{BM2 Ion Channel}

At the biochemical level, the influenza B virus RNA segment 7 is similar to the influenza A virus RNA segment in coding for two proteins. However, influenza B virus encodes two proteins in RNA segment 7 by using a bicistronic mRNA encoding BM1 and BM2 and using a stop-start of translation and two cistrons in tandem (Horvath et al. 1990). BM2 encodes 109 amino acids. Successful uncoating of the influenza B virus in endosomes requires acidification of the influenza B virus particle (Paterson et al. 2003). When the BM2 protein was expressed in Xenopus oocytes or in mammalian cells, acidification of the cells occurred and the BM2 protein has properties consistent with it being a proton selective ion channel. The transmembrane domain of BM2 and influenza A virus M2 protein both contain the motif HXXXW, and for both proteins the His and Trp residues are important for channel function (Mould et al. 2003). Like the A/M2 protein,
$\mathrm{B} / \mathrm{M} 2$ is a four-helix bundle and the atomic structure was determined by NMR (Wang et al. 2009). However, BM2 is not blocked by amantadine because overall its pore has a different amino acid sequence from A/M2. Thus, influenza $\mathrm{A}$ virus and influenza $\mathrm{B}$ virus both encode proton-selective ion channels using the same ion mechanism, but the two viruses encode the two proteins in different RNA segments and by different strategies (Mould et al. 2003).

\section{INFLUENZA C VIRUS ION CHANNEL}

There is some evidence that influenza $\mathrm{C}$ virus has an ion channel activity. It has been found that the influenza $\mathrm{C}$ virus $\mathrm{CM} 2$ protein, which is a small integral membrane protein that spans the membrane once, can alter intracellular $\mathrm{pH}$, and its transmembrane domain can substitute for that of influenza A virus AM2 protein and can support infectious virus production (Stewart and Pekosz 2012). However, electrophysiological recordings have not been made to verify ion channel activity.

\section{CONCLUDING REMARKS}

Influenza A and B virus AM2 and BM2 proteins are two of the smallest ion channels identified to date, and influenza A virus AM2 protein is the target for inhibition by the antiviral drug amantadine hydrochloride. The channels are proton-selective, and a histidine and a tryptophan are the proton sensor and the channel gate, respectively. The influenza A virus AM2 protein forms an amantadine-sensitive channel, but the influenza B virus BM2 ion channel is not sensitive to amantadine. The structure of structure of AM2 has been determined by X-ray crystallography, by solution NMR, and by solid phase NMR, and for BM2 by solution NMR, and thus the AM2 and BM2 ion channels have become among the most studied ion channels in biology.

\section{ACKNOWLEDGMENT}

This article has been made freely available online courtesy of TAUNS Laboratories. 


\author{
Influenza Virus AM2 and BM2 Ion Channels
}

\section{REFERENCES}

Beale R, Wise H, Stuart A, Ravenhill BJ, Digard P, Randow F 2014. A LC3-interacting motif in the influenza A virus M2 protein is required to subvert autophagy and maintain virion stability. Cell Host Microbe 15: 239-247. doi:10 .1016/j.chom.2014.01.006

Cady SD, Schmidt-Rohr K, Wang J, Soto CS, Degrado WF, Hong M. 2010. Structure of the amantadine binding site of influenza M2 proton channels in lipid bilayers. Nature 463: 689-692. doi:10.1038/nature08722

Chizhmakov IV, Geraghty FM, Ogden DC, Hayhurst A, Antoniou M, Hay AJ. 1996. Selective proton permeability and $\mathrm{pH}$ regulation of the influenza virus $\mathrm{M} 2$ channel expressed in mouse erythroleukaemia cells. J Physiol 494: 329-336. doi:10.1113/jphysiol.1996.sp021495

Ciampor F, Bayley PM, Nermut MV, Hirst EM, Sugrue RJ, Hay AJ. 1992a. Evidence that the amantadine-induced, M2-mediated conversion of influenza A virus hemagglutinin to the low $\mathrm{pH}$ conformation occurs in an acidic trans Golgi compartment. Virology 188: 14-24. doi:10.1016/ 0042-6822(92)90730-D

Ciampor F, Thompson CA, Grambas S, Hay AJ. 1992b. Regulation of $\mathrm{pH}$ by the $\mathrm{M} 2$ protein of influenza A viruses. Virus Res 22: 247-258. doi:10.1016/0168-1702(92) 90056-F

Davies WL, Grunert RR, Haff RF, McGahen JW, Neumayer EM, Paulshock M, Watts JC, Wood TR, Herman EC, Hoffman CE. 1964. Antiviral activity of 1-adamantanamine (amantadine). Science 144: 862-863. doi:10 $.1126 /$ science.144.3620.862

Duong-Ly KC, Nanda V, DeGrado WF, Howard KP. 2005. The conformation of the pore region of the M2 proton channel depends on lipid bilayer environment. Protein Sci 14: 856-861. doi:10.1110/ps.041185805

Grambas S, Hay AJ. 1992. Maturation of influenza A virus hemagglutinin-estimates of the $\mathrm{pH}$ encountered during transport and its regulation by the M2 protein. Virology 190: 11-18. doi:10.1016/0042-6822(92)91187-Y

Grambas S, Bennett MS, Hay AJ. 1992. Influence of amantadine resistance mutations on the $\mathrm{pH}$ regulatory function of the M2 protein of influenza A viruses. Virology 191: 541-549. doi:10.1016/0042-6822(92)90229-I

Grantham ML, Stewart SM, Lalime EN, Pekosz A. 2010 Tyrosines in the influenza A virus M2 protein cytoplasmic tail are critical for production of infectious virus particles. J Virol 84: 8765-8776. doi:10.1128/JVI.00853-10

Gu RX, Liu LA, Wei DQ. 2013. Structural and energetic analysis of drug inhibition of the influenza A M2 proton channel. Trends Pharmacol Sci 34: 571-580. doi:10.1016/j .tips.2013.08.003

Hay AJ, Wolstenholme AJ, Skehel JJ, Smith MH. 1985. The molecular basis of the specific anti-influenza action of amantadine. EMBO J 4: 3021-3024. doi:10.1002/j.14602075.1985.tb04038.x

Horvath CM, Williams MA, Lamb RA. 1990. Eukaryotic coupled translation of tandem cistrons: identification of the influenza B virus BM2 polypeptide. EMBO J 9: 26392647. doi:10.1002/j.1460-2075.1990.tb07446.x

Hu F, Luo W, Cady SD, Hong M. 2011. Conformational plasticity of the influenza A M2 transmembrane helix in lipid bilayers under varying $\mathrm{pH}$, drug binding, and mem- brane thickness. Biochim Biophys Acta 1808: 415-423. doi:10.1016/j.bbamem.2010.09.014

Hughey PG, Compans RW, Zebedee SL, Lamb RA. 1992. Expression of the influenza A virus M2 protein is restricted to apical surfaces of polarized epithelial cells. J Virol 66: 5542-5552.

Hull JD, Gilmore R, Lamb RA. 1988. Integration of a small integral membrane protein, $\mathrm{M} 2$, of influenza virus into the endoplasmic reticulum: analysis of the internal signalanchor domain of a protein with an ectoplasmic $\mathrm{NH} 2$ terminus. J Cell Biol 106: 1489-1498. doi:10.1083/jcb .106 .5 .1489

Inglis SC, McGeoch DJ, Mahy BWJ. 1977. Polypeptides specified by the influenza virus genome 2. Assignment of protein coding functions to individual genome segments by in vitro translation. Virology 78: 522-536. doi:10.1016/0042-6822(77)90128-3

Jackson D, Lamb RA. 2008. The influenza A virus spliced messenger RNA M mRNA3 is not required for viral replication in tissue culture. J Gen Virol 89: 3097-3101. doi:10.1099/vir.0.2008/004739-0

Jagger BW, Wise HM, Kash JC, Walters K-A, Wills NM, Xiao Y-L, Dunfee RL, Schwartzman LM, Ozinsky A Bell GL, et al. 2012. An overlapping protein-coding region in influenza A virus segment 3 modulates the host response. Science 337: 199-204. doi:10.1126/science .1222213

Lamb RA, Choppin PW. 1979. Segment 8 of the influenza virus genome is unique in coding for two polypeptides. Proc Natl Acad Sci 76: 4908-4912. doi:10.1073/pnas.76 .10 .4908

Lamb RA, Choppin PW. 1981. Identification of a second protein (M2) encoded by RNA segment 7 of influenza virus. Virology 112: 729-737. doi:10.1016/0042-6822 (81) $90317-2$

Lamb RA, Peluso RW, Choppin PW. 1978. SV5 and Sendai virus polypeptides: aspects of composition, synthesis and phosphorylation. In Negative strand viruses and the host cell (ed. Mahy BWJ, Barry RD), pp. 195-203. Academic, London.

Lamb RA, Choppin PW, Chanock RM, Lai CJ. 1980. RNA segment 8 of the influenza virus genome contains two overlapping genes: mapping the genes for polypeptides NS1 and NS2. In Structure and variation in influenza virus (ed. Laver G, Air G), pp. 91-95. Elsevier, New York.

Leiding T, Wang J, Martinsson J, DeGrado WF, Arskold SP. 2010. Proton and cation transport activity of the M2 proton channel from influenza A virus. Proc Natl Acad Sci 107: 15409-15414. doi:10.1073/pnas.1009997107

Liu H, Grantham ML, Pekosz A. 2018. Mutations in the influenza $A$ virus $M 1$ protein enhance virus budding to complement lethal mutations in the M2 cytoplasmic tail. J Virol 92: e00858-17.

Martin K, Heleniust A. 1991. Nuclear transport of influenza virus ribonucleoproteins: the viral matrix protein (M1) promotes export and inhibits import. Cell 67: 117-130. doi:10.1016/0092-8674(91)90576-K

McCown MF, Pekosz A. 2005. The influenza A virus $\mathrm{M}_{2}$ cytoplasmic tail is required for infectious virus production and efficient genome packaging. J Virol 79: 35953605. doi:10.1128/JVI.79.6.3595-3605.2005 
R.A. Lamb

Mould JA, Paterson RG, Takeda M, Ohigashi Y, Venkataraman P, Lamb RA, Pinto LH. 2003. Influenza B virus BM2 protein has ion channel activity that conducts protons across membranes. Dev Cell 5: 175-184. doi:10.1016/ S1534-5807(03)00190-4

Muramoto Y, Noda T, Kawakami E, Akkina R, Kawaoka Y. 2013. Identification of novel influenza A virus proteins translated from PA mRNA. J Virol 87: 2455-2462. doi:10.1128/JVI.02656-12

Nishimura K, Kim S, Zhang L, Cross TA. 2002. The closed state of a $\mathrm{H}^{+}$channel helical bundle combining precise orientational and distance restraints from solid state NMR. Biochemistry 41: 13170-13177. doi:10.1021/ bi0262799

Palese P. 1977. The genes of influenza virus. Cell 10: 1-10. doi:10.1016/0092-8674(77)90133-7

Paterson RG, Takeda M, Ohigashi Y, Pinto LH, Lamb RA. 2003. Influenza B virus BM2 protein is an oligomeric integral membrane protein expressed at the cell surface. Virology 306: 7-17. doi:10.1016/S0042-6822(02)00083-1

Pielak RM, Schnell JR, Chou JJ. 2009. Mechanism of drug inhibition and drug resistance of influenza A M2 channel. Proc Natl Acad Sci 106: 7379-7384. doi:10.1073/pnas .0902548106

Pinto LH, Shimbo K, Brassard DL, Lamb RA. 1996. Electrical properties of the M2 ion channel of influenza A virus. In Options for the control of influenza III (ed. Brown LE Hampson AW, Webster RG), pp. 333-342. Elsevier, Cairns, Australia.

Pinto LH, Dieckmann GR, Gandhi CS, Papworth CG, Braman J, Shaughnessy MA, Lear JD, Lamb RA, DeGrado WF. 1997. A functionally defined model for the M2 proton channel of influenza A virus suggests a mechanism for its ion selectivity. Proc Natl Acad Sci 94: 11301-11306. doi:10.1073/pnas.94.21.11301

Rossman JS, Jing X, Leser GP, Balannik V, Pinto LH, Lamb RA. 2010a. Influenza virus M2 ion channel protein is necessary for filamentous virion formation. J Virol 84: 5078-5088. doi:10.1128/JVI.00119-10

Rossman JS, Jing X, Leser GP, Lamb RA. 2010b. Influenza virus M2 protein mediates ESCRT-independent membrane scission. Cell 142: 902-913. doi:10.1016/j.cell .2010.08.029

Schnell JR, Chou JJ. 2008. Structure and mechanism of the M2 proton channel of influenza A virus. Nature 451: 591 595. doi:10.1038/nature 06531

Shimbo K, Brassard DL, Lamb RA, Pinto LH. 1996. Ion selectivity and activation of the M2 ion channel of influenza virus. Biophys J 70: 1335-1346. doi:10.1016/S00063495(96)79690-X

Stewart SM, Pekosz A. 2012. The influenza C virus CM2 protein can alter intracellular $\mathrm{pH}$, and its transmembrane domain can substitute for that of the influenza A virus M2 protein and support infectious virus production. J Virol 86: 1277-1281. doi:10.1128/JVI.05681-11

Stouffer AL, Acharya R, Salom D, Levine AS, Di Costanzo L, Soto CS, Tereshko V, Nanda V, Stayrook S, DeGrado WF. 2008. Structural basis for the function and inhibition of an influenza virus proton channel. Nature 451: 596-599. doi:10.1038/nature06528

Su WC, Yu WY, Huang SH, Lai MMC. 2018. Ubiquitination of the cytoplasmic domain of influenza A virus M2 protein is crucial for production of infectious virus particles. J Virol 92: e01972-17.

Sugrue RJ, Bahadur G, Zambon MC, Hall-Smith M, Douglas AR, Hay AJ. 1990. Specific structural alteration of the influenza haemagglutinin by amantadine. EMBO J 9: 3469-3476. doi:10.1002/j.1460-2075.1990.tb07555.x

Thomaston JL, Alfonso-Prieto M, Woldeyes RA, Fraser JS, Klein ML, Fiorin G, DeGrado WF. 2015. High-resolution structures of the M2 channel from influenza A virus reveal dynamic pathways for proton stabilization and transduction. Proc Natl Acad Sci 112: 14260-14265. doi:10.1073/ pnas. 1518493112

von Heijne G, Gavel Y. 1988. Topogenic signals in integral membrane proteins. Eur J Biochem 174: 6711-6718.

Wang J, Kim S, Kovacs F, Cross TA. 2001. Structure of the transmembrane region of the M2 protein $\mathrm{H}^{+}$channel. Protein Sci 10: 2241-2250. doi:10.1110/ps.17901

Wang J, Pielak RM, McClintock MA, Chou JJ. 2009. Solution structure and functional analysis of the influenza B proton channel. Nat Struct Mol Biol 16: 1267-1271. doi:10 $.1038 / \mathrm{nsmb} .1707$

Wise HM, Hutchinson EC, Jagger BW, Stuart AD, Kang ZH, Robb N, Schwartzman LM, Kash JC, Fodor E, Firth AE. 2012. Identification of a novel splice variant form of the influenza A virus M2 ion channel with an antigenically distinct ectodomain. PLoS Pathog 8: e1002998. doi:10 .1371/journal.ppat.1002998

Yi M, Cross TA, Zhou HX. 2009. Conformational heterogeneity of the M2 proton channel and a structural model for channel activation. Proc Natl Acad Sci 106: 13311-13316. doi:10.1073/pnas.0906553106

Zebedee SL, Lamb RA. 1988. Influenza A virus M2 protein: monoclonal antibody restriction of virus growth and detection of M2 in virions. J Virol 62: 2762-2772.

Zebedee SL, Richardson CD, Lamb RA. 1985. Characterization of the influenza virus M2 integral membrane protein and expression at the infected-cell surface from cloned cDNA. J Virol 56: 502-511.

Zhirnov OP. 1990. Solubilization of matrix protein M1/M from virions occurs at different $\mathrm{pH}$ for orthomyxo- and paramyxoviruses. Virology 176: 274-279. 


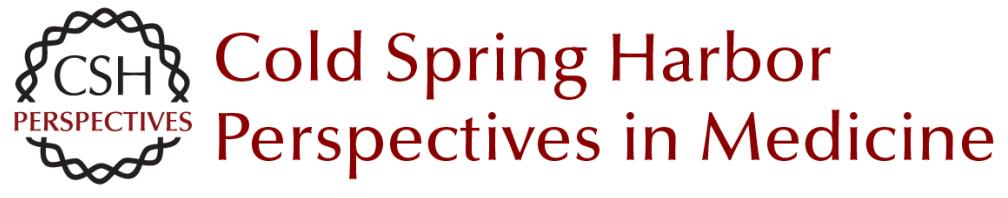

\section{The Structure, Function, and Pathobiology of the Influenza A and B Virus Ion Channels}

Robert A. Lamb

Cold Spring Harb Perspect Med 2020; doi: 10.1101/cshperspect.a038505 originally published online January 27, 2020

Subject Collection Influenza: The Cutting Edge

Emerging HxNy Influenza A Viruses
William J. Liu, Yan Wu, Yuhai Bi, et al.
Equine Influenza
Thomas M. Chambers
Human Influenza Epidemiology
Sukhyun Ryu and Benjamin J. Cowling

Host Cell Factors That Interact with Influenza

Virus Ribonucleoproteins

Ecco Staller and Wendy S. Barclay

Induction and Evasion of Type-I Interferon

Responses during Influenza A Virus Infection

Raquel Muñoz-Moreno, Carles Martínez-Romero and Adolfo García-Sastre

Structure and Function of Influenza Polymerase Joanna M. Wandzik, Tomas Kouba and Stephen Cusack

H7N9 Influenza Virus in China

Chengjun Li and Hualan Chen

H5 Influenza Viruses in Egypt Rabeh El-Shesheny, Ahmed Kandeil, Ahmed Mostafa, et al.
Antivirals Targeting the Neuraminidase

Larisa Gubareva and Teena Mohan

Accessory Gene Products of Influenza A Virus Rute M. Pinto, Samantha Lycett, Eleanor Gaunt, et al.

Influenza Immunization in the Context of

Preexisting Immunity

Susanne L. Linderman, Ali H. Ellebedy, Carl Davis, et al.

Hemagglutinin Structure and Activities Steven J. Gamblin, Sébastien G. Vachieri, Xiaoli Xiong, et al.

Live Attenuated Cold-Adapted Influenza Vaccines Kanta Subbarao

Next-Generation Influenza Vaccines Masaru Kanekiyo and Barney S. Graham

\section{Selective Genome Packaging Mechanisms of Influenza A Viruses \\ Takeshi Noda}

Systems Biological Analysis of Immune Response to Influenza Vaccination

Mario Cortese, Amy C. Sherman, Nadine G.

Rouphael, et al.

For additional articles in this collection, see http://perspectivesinmedicine.cshlp.org/cgi/collection/ 